\title{
BMJ Open Long-term trends of hospital admissions among patients with cancer following the 2015 earthquake: a single institution observational study in Kathmandu, Nepal
}

To cite: Uprety A, Ozaki A, Higuchi $A$, et al. Longterm trends of hospital admissions among patients with cancer following the 2015 earthquake: a single institution observational study in Kathmandu, Nepal. BMJ Open 2019;9:e026746. doi:10.1136/ bmjopen-2018-026746

- Pre-publication and additional material is published online only. To view please visit the journal online (http://dx.doi. org/10.1136/bmjopen-2018026746).

Received 23 September 2018 Revised 27 March 2019 Accepted 15 May 2019

Check for updates

(C) Author(s) (or their employer(s)) 2019. Re-use permitted under CC BY-NC. No commercial re-use. See rights and permissions. Published by BMJ.

For numbered affiliations see end of article.

Correspondence to

Ms. Asaka Higuchi;

a.higuchi1025@gmail.com

\section{ABSTRACT}

Objectives Little is known regarding how natural disasters affect patients with cancer in low-income and middle-income countries. The objective of the present study was to assess the impact of the 2015 Nepal earthquake on the admission of patients with cancer at a core medical institution in Kathmandu.

Design, setting and participants We considered all 3520 cancer patient admissions to Tribhuvan University Teaching Hospital, from 25 April 2013 to 24 April 2017 (2 years before and 2 years after the earthquake).

Outcome measures The number of cancer patient admissions was calculated for each month. Using a negative binomial model, we estimated the incidence rate ratio (IRR) for admission numbers each month after the earthquake compared with the pre-earthquake baseline and investigated chronological change.

Results The total admission number in the first month after the earthquake was decreased compared with that of the predisaster baseline (IRR $=0.66,95 \% \mathrm{Cl} 0.43$ to 1.00 ), which largely reflected decreased admissions of patients from outside of the most disaster-affected districts. From the second month, the admission number consistently exceeded the predisaster baseline for the remaining postdisaster period. In contrast to the month of the disaster, the continuation of increased admissions was most prominent among those from outside of the most affected districts.

Conclusions After a transient decrease immediately following the 2015 Nepal earthquake, there was a longterm increase in cancer patient admissions in a core hospital in Kathmandu. These changes were seen most prominently in patients from outside the most disaster affected areas.

\section{INTRODUCTION}

Cancer is a major cause of global health burden, with approximately 17.5 million new diagnoses and 8.7 million deaths in 2015 . $^{1}$ Although early detection and treatment are both essential components in cancer

\section{Strengths and limitations of this study}

To the best of our knowledge, this study is the first to investigate long-term access to cancer care after a disaster in a low-income country, through time trends of hospital admissions for cancer following the 2015 Nepal earthquake.

- This study only included data from Tribhuvan University Teaching Hospital, and generalisability of the observed findings may be limited.

- This study is limited because the clinical contexts of each admission lacked detailed information on clinical characteristics, process of referrals, treatment details and outcomes, and experiences of the earthquakes.

management, ${ }^{2}$ multiple demographic, clinical and psychosocial factors contribute to delayed cancer detection and treatment, including old age, ${ }^{3}$ being a racial minority, ${ }^{3}$ cancer types, ${ }^{4}$ natures of symptoms, ${ }^{34}$ limited cancer awareness, ${ }^{3}{ }^{4}$ employment status, ${ }^{5}$ lower socioeconomic status, ${ }^{4}$ poor social support, ${ }^{3}$ lower regional developments, ${ }^{2}$ and rurality. ${ }^{6}$ These diverse characteristics are associated with restricted access to timely cancer care, which can lead to worsened survival. $^{7}$

There has additionally been rising attention on the adverse effects of natural disasters on access to cancer care. Worldwide, more than 524000 people died and US\$ 3.16 trillion in Purchasing Power Parities were lost due to 110000 extreme weather events from 1997 to $2016,{ }^{8}$ and such impacts are projected to increase with the progression of climate change. ${ }^{9}$ It has been reported that natural disasters can worsen cancer care access in the 
short term. ${ }^{1011}$ Further, recent studies have suggested that the impact of large-scale disasters on cancer care also persist in long-term, adversely affecting cancer patient outcomes. ${ }^{12} 13$ Yet, such evidence is predominantly collected from disasters in high-income countries (HICs), and information is limited regarding cancer care impacts of disasters experienced in lowand middle-income countries (LMICs). There could be significant disparities in resources available after disasters, as well as in general health systems and local conditions, between HICs and LMICs. Thus, instead of directly applying the findings observed in HICs, it is imperative to investigate health effects of disasters on cancer in LMICs, and to construct a LMIC-specific body of evidence. ${ }^{14}$ This area of research is crucial, given that LMICs are experiencing increased health burdens of both cancer and natural disasters. ${ }^{28}$

Nepal is a country located in South Asia, and is an LMIC with the gross national income per capita of US\$730 in 2016..$^{15}$ According to the nationwide hospital based cancer registry, the number of cancer diagnoses in the country increased from 3251 (per total population of 25.0 million) in 2003 to 8729 (per total population of 28.0 million) in $2013,{ }^{16}$ and the burden of cancer is on the rise. On 25 April 2015, an earthquake measuring 7.8 on the Richter scale with the epicentre of Gorkha (figure 1) struck broad areas of Nepal, followed by numerous aftershocks, including the one which severely affected Dolakha (figure 1) on 12 May 2015, resulting in approximately 9000 deaths, 23000 injuries and two million displaced people. ${ }^{17}$ Further, approximately 1000 health facilities collapsed in the earthquakes. ${ }^{17}$ Resultantly, a majority of hospitals and clinics in the affected areas were forced into immediate closure, while a few core medical institutions continued operating. ${ }^{18}$
Before the earthquake, organised cancer care had been provided in a small number of hospitals in Nepal. ${ }^{19}$ Core hospitals had provided necessary examinations and treatments to those from all across the country, and patients, particularly those living in remote areas, often travelled long distances to seek quality care. After the earthquake, the closure of vulnerable hospitals and continuation of relatively robust core hospitals may have exacerbated disparities in cancer care. It is conceivable that patterns of healthcare utilisation in patients after the disaster could have depended on earthquake damage and pre-existing resources for cancer care in their dwelling areas, as shown in the aftermath of previous disasters. ${ }^{12}{ }^{13}$ We attempted to capture such changes, using a time trend analysis of the number of cancer patient admissions in one core hospital.

The objectives of the present study were twofold: (1) to assess the long-term effects of the 2015 Nepal earthquake on the number of cancer patient admissions at a core medical institution through comparison with admissions in the pre-earthquake period; and (2) to assess whether any such effects were mediated by geographical access and the extent of earthquake damage in patient dwelling areas.

\section{MATERIAL AND METHODS \\ Study settings and participants}

The study site was Tribhuvan University Teaching Hospital (TUTH), which is located in Kathmandu, Nepal (figure 1). As of 18 March 2018, the hospital has 22 departments and 656 beds, and its total admission number in the fiscal year of 2016/2017 was 24852 , with the average lengths of the hospital stay being 7.2 days. Due to its large capacity, the hospital has served as a key medical institution, not only for residents of Kathmandu (1 309000 in 2018), but also for those living outside

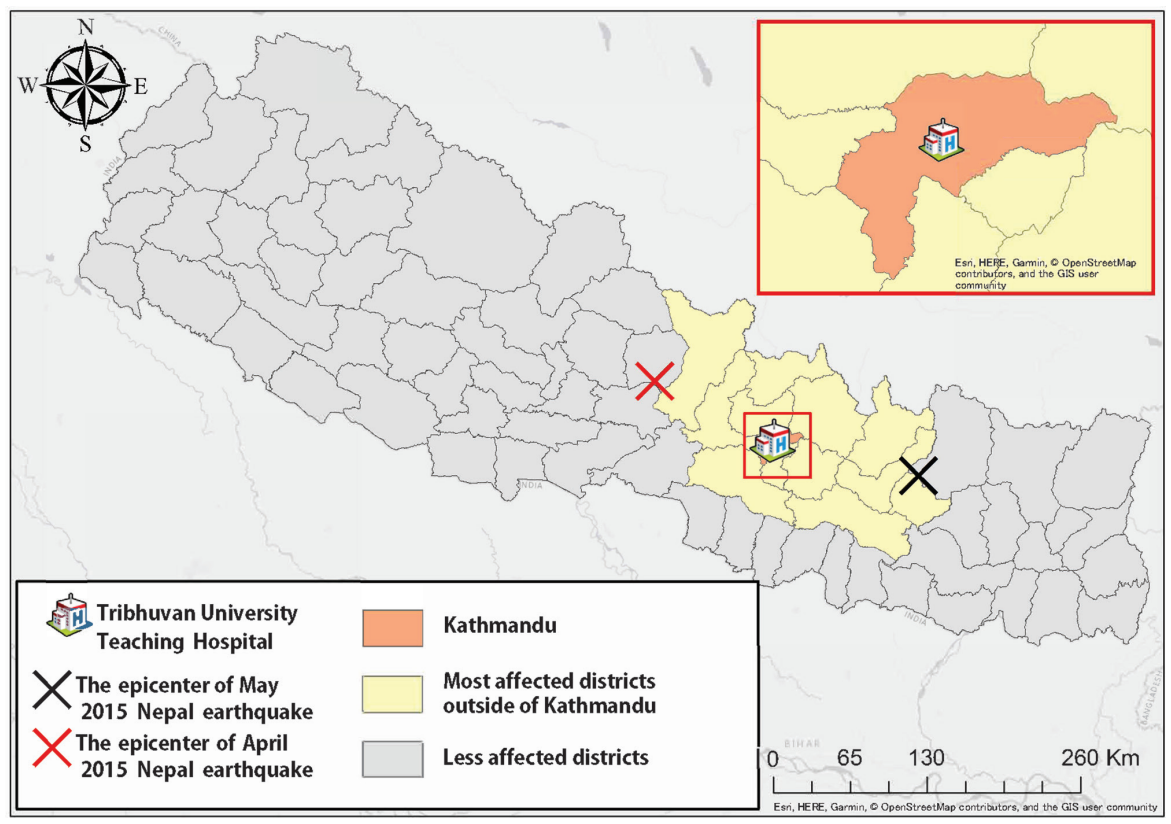

Figure 1 Map of Nepal. The epicentres of the two earthquakes and the study site, Tribhuvan University Teaching Hospital, are delineated, with the classification of the districts depending on the severity of the earthquake damage. 
of the capital (28 253900 in 2018). In terms of cancer care, the fundamental diagnostic measures (eg, tumour markers, histopathology and imaging studies) and treatment measures (eg, surgeries) have been available at TUTH, while patients needing certain types of chemotherapy and/or radiation therapy have been referred to other institutions more specialised in cancer care. TUTH is one of twelve medical institutions which comprise the nationwide cancer registry in Nepal as of $2013 .{ }^{16}$ Furthermore, TUTH was one of the limited medical institutions which continuously provided healthcare and coped with overwhelming healthcare needs in the area stricken by the 2015 Nepal earthquake. ${ }^{20}$

All patients admitted to TUTH with the primary diagnosis for admission being cancer, 2 years before and after the earthquake (25 April 2013 to 24 April 2017), were included in this study. The study period was determined to assess any long-term changes before and after the earthquake, and was separated into the pre-earthquake period (730 days, from 25 April 2013 to 24 April 2015) and the postearthquake period (731 days, from 25 April 2015 to 24 April 2017). In core hospitals in Nepal, many patients with cancer are only admitted once for initial examinations and treatments, however are usually not admitted after this initial event, unless additional interventions, such as treatment for recurrent disease or complications, is required. For the patients who were admitted multiple times for cancer during the study period, only the first admission was considered in the following analyses, in order to focus on this initial examination and treatment event.

\section{Data sources}

To extract relevant patient data, we used the electronic database in the administrative office of TUTH as the primary data source. Although detailed records of the admitted patients at TUTH have been preserved on a paper chart basis, basic patient information (ie, names, primary diagnoses, etc) have also been stored in this electronic database. We included patients with any type of malignancy. The primary diagnoses were recorded in the database, following the International Classification of Diseases and Health-related Problems, 10th Revision. The patients with the codes of malignant neoplasms (C00C97) and in situ neoplasm (D00-D09) were eligible for our study.

\section{Analytical data}

From the digital database, we extracted the following variables for each patient: demographic factors (sex, age and residential addresses), primary diagnoses, types of admitted wards and the admission dates.

For a proxy measure for severity of the earthquake damage in patient dwelling areas, we used the definition applied by the Nepali Government. Immediately following the 2015 earthquake, the government designated the 14 most affected districts (MADs) (Gorkha, Kavrepalanchok, Dhading, Nuwakot, Rasuwa,
Sindupalchok, Dolakha, Ramechhap, Okhaldunga, Makwanpur, Sindhuli, Kathmandu, Bhaktapur and Lalitpur) (figure 1), in which 1814000 people and 410894 buildings were impacted by the earthquake as of 15 May $2015 .{ }^{21}$ The residents of the MADs later became potential targets for the Earthquake Housing Reconstruction Multi-Donor Trust Fund by the government, ${ }^{22}$ and this definition was widely recognised among international organisations such as the United Nations Office for the Coordination of Humanitarian Affairs. ${ }^{21}$ To take into account any effect of the geographical distance to TUTH on admissions, the MADs were further separated into Kathmandu and the MADs outside of Kathmandu (MADOKs). For the sake of simplicity, we defined the areas outside of the MADs as the less affected districts (LADs). In general, the districts located in LADs were more distant from TUTH compared with MADOKs.

\section{Data analysis}

In order to assess chronological change in cancer patient admission numbers, we calculated monthly figures throughout the study period, by defining the month of the earthquake (from 25 April 2015 to 24 May 2015) as month 0 . We set months from 0 to 23 after the earthquake in chronological order, and the month from -1 to -24 before the earthquake in reverse chronological order. We defined postdisaster years one and two, corresponding to months 0 to 11 and 12 to 23 , respectively.

With the above data, we performed three analyses. First, we examined underlying seasonal patterns or cohort effects in the data through assessing chronological change in monthly admission numbers. Second, we compared the admission number each month after the earthquake with the pre-earthquake baseline, using a negative binomial model for the monthly admission number, with year (predisaster baseline, year one, or year two, age (-20], (20-40], (40-60], (60-80], or (80-) and sex (female or male) as covariates. The dataset was appropriately reshaped to fit the negative binomial model with dummy variables for age and sex for the explanation of the monthly admission number. ${ }^{23}$ This model was selected as we assumed no excess-zero, but over-dispersion in this outcome. ${ }^{24}$ In order to minimise any seasonal/monthly effect on the data, we constructed regression models for each month separately, following a previous study (eg, both months 0 and 12 were compared with months -12 and -24). ${ }^{11}$ The primary interest of this analysis was comparisons between year one and two versus the pre-earthquake baseline with respect to the variable 'year'. Separate models were also constructed depending on the severity of the earthquake damage in patient dwelling areas. As sensitivity analysis, we compared the total admission number after the earthquake with the predisaster baseline, using a negative binomial model, while adjusting for seasonal patterns, age and sex, as covariates. We defined four seasons as follows: spring (March to May), summer (June to August), autumn (September to November) and winter (December to February). Third, to facilitate the 
recognition of the overall time-series patterns in the incidence rate ratios (IRRs) and their differences among the dwelling areas, we created a graph of the smoothed values for the IRRs throughout the postdisaster period. We used Stata V.14.0. for all analyses.

\section{Patient and public involvement}

The present study is a retrospective analysis of the existing database, and we did not include the patients and other population in particular in the development of the study design.

\section{RESULTS}

\section{Patient characteristics}

The number of patients with cancer admitted to TUTH during the study period was 3520 . The number of patients in the pre-earthquake and postearthquake period was $1404(39.9 \%)$ and $2116(60.1 \%)$, respectively, increasing by 712. All identified patients were included in the following analyses. Among them, 65 (1.8\%) and seven $(0.2 \%)$ patients were admitted to TUTH two and three times, respectively, and in these cases we only considered data from the first admission.

Table 1 shows the characteristics of the pre-earthquake and post-earthquake patients. There was an increase in cancer among younger individuals less than 20 years of age postdisaster compared with predisaster (228 vs 88 ). Other than this, there were no clinically meaningful differences in the distributions of age and sex before and after the earthquake. Among three categories of the severity of disaster damage in dwelling areas, the postearthquake increase in admission numbers was largest from the LADs (1047 vs 639). Concerning the diagnostic type of cancer, increased admission was observed for digestive organs (616 vs 440), eye, brain, and other types of central nervous system (133 vs 23), and for lymphoid, haematopoietic and related tissue (174 vs 11), while a decrease was observed for urinary tract related cancers (156 vs 281). When we assessed admissions by ward type, the largest increase was observed in the internal medicine ward (652 vs 195).

Table 2 summarises the postearthquake patient characteristics according to districts divided by the severity of damage. There were no clinically meaningful differences in age, sex, the diagnostic type of cancer and ward before and after the earthquake, when patients were divided by district.

\section{Assessment of potential seasonal-effects and cohort-effects}

Figure 2 shows chronological change of the number of monthly cancer patient admissions throughout the study period. There was a steep increase in the number of admissions in month 1 . The total admission number in month 12 was 118 (online supplementary material 1 ), and this was the largest figure in the postearthquake period. Before the earthquake, no seasonal effects or upward trends, which might reflect a cohort effect, were observed. This implicates restricted influence of seasonal or cohort effects on the observed increase in the admission number after the earthquake.

\section{Time trend of the number of admissions before and after the earthquake}

Figures 3-6 show chronological change of the estimated IRR for the number of the monthly admissions during the postdisaster period, which were computed through month-specific regression models. Figures 3-6, respectively correspond to the admission data of all patients, those from Kathmandu, those from the MADOKs and those from the LADs. The admission number in month 0 was significantly decreased compared with the predisaster baseline (IRR $=0.66,95 \%$ CI 0.43 to 1.00 ) (online supplementary material 2). Yet, the monthly admission number consistently exceeded the predisaster baseline for the remaining postdisaster period, with statistically significant increases in IRRs observed in 8 months of year one and 7 months of year two.

There was a significant disparity in the time trends of admission numbers depending on patient dwelling areas, which were categorised according to the severity of damage. In the patients living in LADs, a significant decrease in the admission number was observed in month 0 (IRR $=0.37,95 \%$ CI 0.19 to 0.74 ), and after that, significant increases of the admission number were observed in 10 months of year one, and 8 months of year two. In those living in the MADOKs, a significant increase in admission numbers was observed in 8 months of year one, but only in 2 months of year two. In those living in Kathmandu, significant increases in the admission numbers were observed only in 2 months of both years one and two.

In the reshaped dataset, the mean monthly admission number was smaller than its variance (2.4 vs 6.6 ), which suggested the existence of over-dispersion. In contrast, no excess zeros were observed $(25.5 \%, 367 / 1,440)$. Thus, we judged it valid to use the negative binomial model for this dataset.

The sensitivity analysis using the whole patient data also showed that there was a significant increase of the cancer patient admission number compared with the predisaster baseline (IRR=1.63, 95\% CI 1.37 to 1.94 ), while there was no significant change in the admission number between four seasons (data not shown).

Figure 7 shows chronological change of the smoothed IRR values for the monthly admission number during the post-earthquake period. There was a steep increase in admission numbers in year one in the MADOKs, yet it gradually decreased after that, recovering to the pre-earthquake baseline at the end of the year two. In contrast, an increase in the LADs developed slowly, and lasted for a period over 2 years. Although an upward trend of the IRRs was observed in Kathmandu in year one, its extent was less prominent compared with other areas. 
Table 1 Participant characteristics pre-disaster and postdisaster

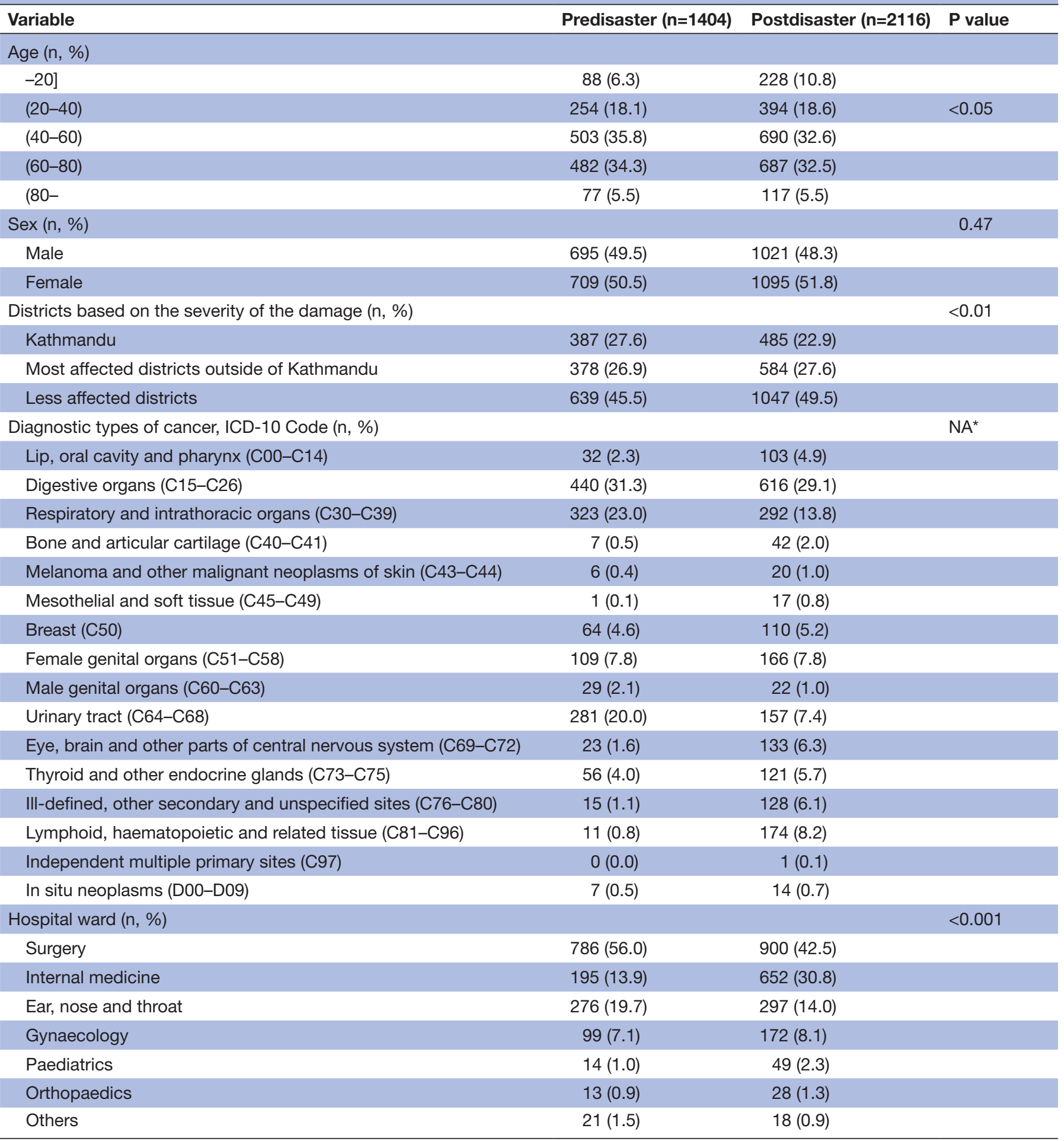

${ }^{*}$ Fisher's exact test did not converge.

ICD-10, International Classification of Diseases and Health-related Problems, 10th Revision.

\section{DISCUSSION}

In the present study, we assessed time trends in cancer patient admission numbers at TUTH for cancer 2 years before and 2 years after the 2015 Nepal earthquake. Admissions decreased in the first month after the earthquake, largely reflecting a decrease among patients from LADs.
However, in the longer term, the number of admissions remained elevated for the rest of the postearthquake period, and such trends persisted the longest in patients from the LADs, followed by the MADOKs and Kathmandu.

These findings suggest a long-lasting and region-specific and damage-specific earthquake impact on access to 
Table 2 Postearthquake patient characteristics according to the districts divided by the severity of damage

\begin{tabular}{|c|c|c|c|}
\hline Variable & Kathmandu (n=485) & $\begin{array}{l}\text { Most affected } \\
\text { districts outside of } \\
\text { Kathmandu }(n=584)\end{array}$ & $\begin{array}{l}\text { Less affected } \\
\text { districts }(n=1047)\end{array}$ \\
\hline \multicolumn{4}{|l|}{ Age $(n, \%)$} \\
\hline-20$]$ & $34(7.0)$ & $60(10.3)$ & $134(12.8)$ \\
\hline$(20-40)$ & $76(15.7)$ & $101(17.3)$ & $217(20.7)$ \\
\hline$(40-60)$ & $164(33.8)$ & $191(32.7)$ & $335(32.0)$ \\
\hline$(60-80)$ & $169(34.9)$ & $196(33.6)$ & $322(30.8)$ \\
\hline$(80-$ & $42(8.7)$ & $36(6.2)$ & $39(3.7)$ \\
\hline \multicolumn{4}{|l|}{$\operatorname{Sex}(n, \%)$} \\
\hline Male & $245(50.5)$ & $264(45.2)$ & $512(48.9)$ \\
\hline Female & $240(49.5)$ & $320(54.8)$ & $535(51.1)$ \\
\hline \multicolumn{4}{|l|}{ Diagnostic types of cancer, ICD-10 Code (n, \%) } \\
\hline Lip, oral cavity and pharynx (CO0-C14) & $24(5.0)$ & $30(5.1)$ & $49(4.7)$ \\
\hline Digestive organs (C15-C26) & $127(26.2)$ & $150(25.7)$ & $339(32.4)$ \\
\hline Respiratory and intrathoracic organs (C30-C39) & $73(15.1)$ & $97(16.6)$ & $122(11.7)$ \\
\hline Bone and articular cartilage (C40-C41) & $15(3.1)$ & $11(1.9)$ & $16(1.5)$ \\
\hline $\begin{array}{l}\text { Melanoma and other malignant neoplasms of skin } \\
\text { (C43-C44) }\end{array}$ & $3(0.6)$ & $9(1.5)$ & $8(0.8)$ \\
\hline Mesothelial and soft tissue (C45-C49) & $3(0.6)$ & $6(1.0)$ & $8(0.8)$ \\
\hline Breast (C50) & $41(8.5)$ & $38(6.5)$ & $31(3.0)$ \\
\hline Female genital organs (C51-C58) & $46(9.5)$ & $40(6.9)$ & $80(7.6)$ \\
\hline Male genital organs (C60-C63) & $4(0.8)$ & $5(0.9)$ & $13(1.2)$ \\
\hline Urinary tract (C64-C68) & $41(8.5)$ & $50(8.6)$ & $66(6.3)$ \\
\hline $\begin{array}{l}\text { Eye, brain and other parts of central nervous } \\
\text { system (C69-C72) }\end{array}$ & $17(3.5)$ & $43(7.4)$ & $73(7.0)$ \\
\hline Thyroid and other endocrine glands (C73-C75) & $19(3.9)$ & $29(5.0)$ & $73(7.0)$ \\
\hline $\begin{array}{l}\text { III-defined, other secondary and unspecified sites } \\
\text { (C76-C80) }\end{array}$ & $29(6.0)$ & $31(5.3)$ & $68(6.5)$ \\
\hline $\begin{array}{l}\text { Lymphoid, haematopoietic and related tissue } \\
\text { (C81-C96) }\end{array}$ & $40(8.3)$ & $44(7.5)$ & $90(8.6)$ \\
\hline Independent multiple primary sites (C97) & $0(0.0)$ & $0(0.0)$ & $1(0.1)$ \\
\hline In situ neoplasms (D00-D09) & $3(0.6)$ & $1(0.2)$ & $10(1.0)$ \\
\hline \multicolumn{4}{|l|}{ Hospital ward (n, \%) } \\
\hline Surgery & $194(40.0)$ & $247(42.3)$ & $459(43.8)$ \\
\hline Internal medicine & $157(32.4)$ & $178(30.5)$ & $317(30.3)$ \\
\hline Ear nose and throat & $73(15.1)$ & $90(15.4)$ & $134(12.8)$ \\
\hline Gynaecology & $45(9.3)$ & $49(8.4)$ & $78(7.5)$ \\
\hline Paediatrics & $6(1.2)$ & $7(1.2)$ & $36(3.4)$ \\
\hline Orthopaedics & $7(1.4)$ & $9(1.5)$ & $12(1.2)$ \\
\hline Others & $3(0.6)$ & $4(0.7)$ & $11(1.1)$ \\
\hline
\end{tabular}

ICD-10, International Classification of Diseases and Health-related Problems, 10th Revision.

cancer care, which is in line with previous studies undertaken in HICs. ${ }^{12} 13$

To our knowledge, no previous studies have investigated the long-term trends of hospital cancer patient admissions after earthquakes in a similar fashion either in HICs or LMICs, however there have been studies examining hospital admissions for other health conditions. Previously, postearthquake increases in hospital admissions and/or emergency department visits have been suggested in infectious diseases, ${ }^{23} 2526$ venous thromboembolism and pulmonary embolism, ${ }^{26}$ cardiovascular diseases, ${ }^{23} 26$ strokes, ${ }^{23}$ chronic respiratory diseases,${ }^{25}$ and 


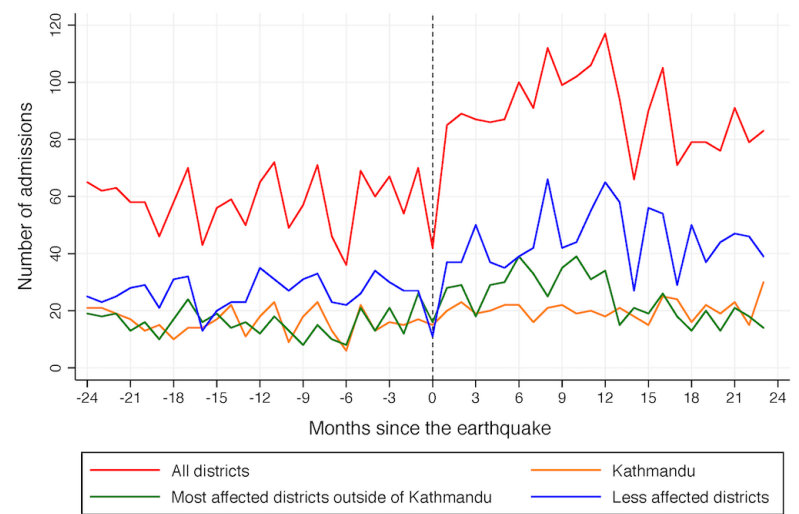

Figure 2 Time trends in the number of monthly admissions throughout the study period. Month 0 was defined as the month of the earthquake (25 April 2015 to 24 May 2015). The pre-earthquake period (25 April 2013 to 24 April 2015) and the postearthquake period (25 April 2015 to 24 April 2017) was divided into month -1 to month -24 in reverse-chronological order, and month 0 to month 23 in chronological order.

gastroduodenal ulcers, ${ }^{27}$ which occurred predominantly during the first several weeks. In contrast, in our study, cancer patient admissions decreased in the first month, but remained elevated for the rest of the 2-year study period.

Such variance may be explained by the difference in the logistics of admissions; patients with conditions analysed in previous studies are typically admitted on the emergency basis, while admissions for patients with cancer are usually scheduled in an elective fashion for examinations as well as for treatments. Thus, the underlying mechanisms of increased or decreased cancer admissions could be different from other conditions, where mental/ physical stresses, temporary unhealthy accommodation,

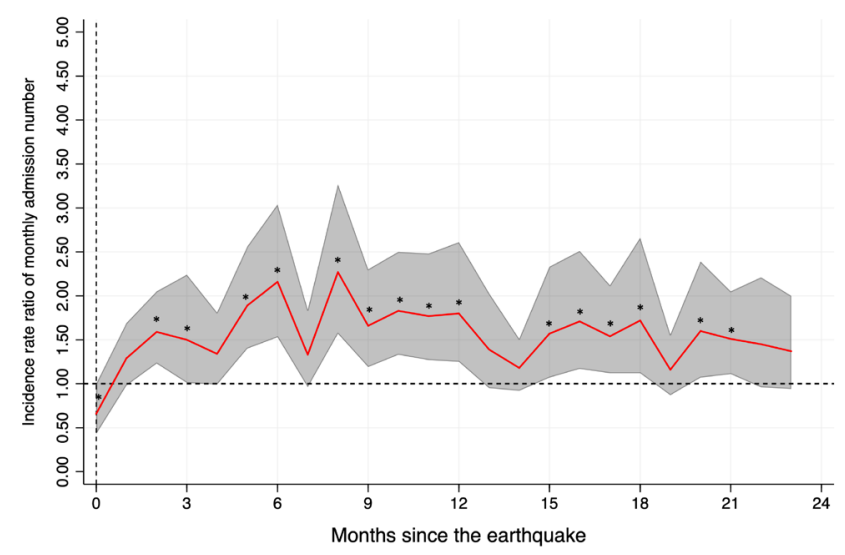

Figure 3 Time trends in the estimated incidence rate ratio for the number of monthly admissions among all patients during the postdisaster period. The pre-earthquake baseline was defined as the monthly admission number from 2013 to 2015 . The incidence rate ratios were adjusted for sex and age, and the asterisk (*) indicates statistical significance at the 0.05 level.

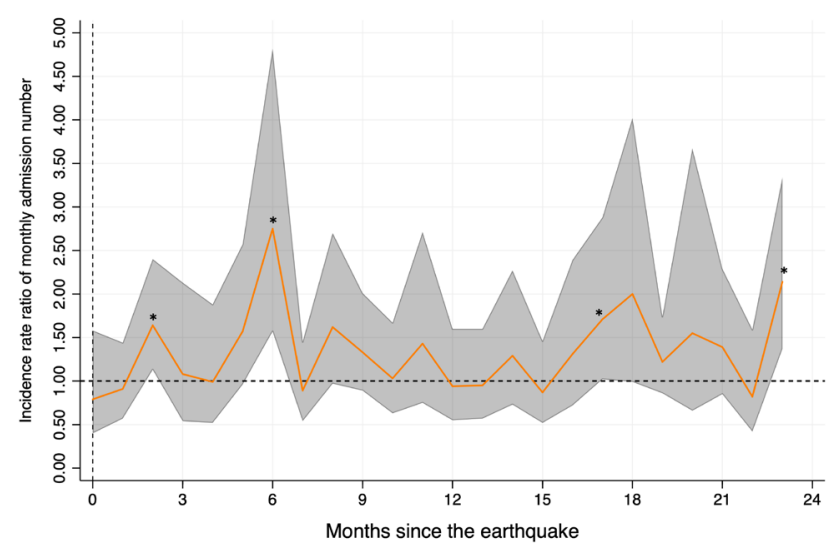

Figure 4 Time trends in the estimated incidence rate ratio for the number of monthly admissions among the patients from Kathmandu during the postdisaster period. The preearthquake baseline was defined as the monthly admission number from 2013 to 2015. The incidence rate ratios were adjusted for sex and age, and the asterisk $\left(^{\star}\right)$ indicates statistical significance at the 0.05 level.

lack of basic necessity (eg, water and food), discontinued regular medications and lifestyle changes (eg, increased salt intake) are regarded as primary contributing factors. ${ }^{23}{ }^{25-27}$ In the following sections, we present the implications of this study separately in the short-term and mid-term to long-term aftermath of the earthquake. The emphasis of the following sections will be placed on the extent of earthquake damage and cancer care resources and access in the local context.

\section{Cancer care in the short-term aftermath of the earthquake}

The transient decrease in the number of admissions mainly occurred among the patients from the LADs. There are four possible explanations for this. First, most

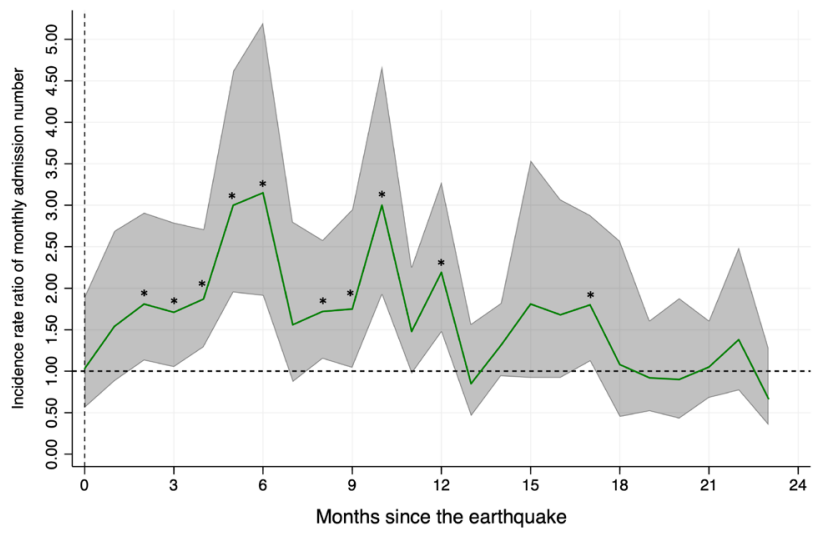

Figure 5 Time trends in the estimated incidence rate ratio for the number of monthly admissions among the patients from the most affected districts outside of Kathmandu during the postdisaster period. The pre-earthquake baseline was defined as the monthly admission number from 2013 to 2015. The incidence rate ratios were adjusted for sex and age, and the asterisk (*) indicates statistical significance at the 0.05 level. 


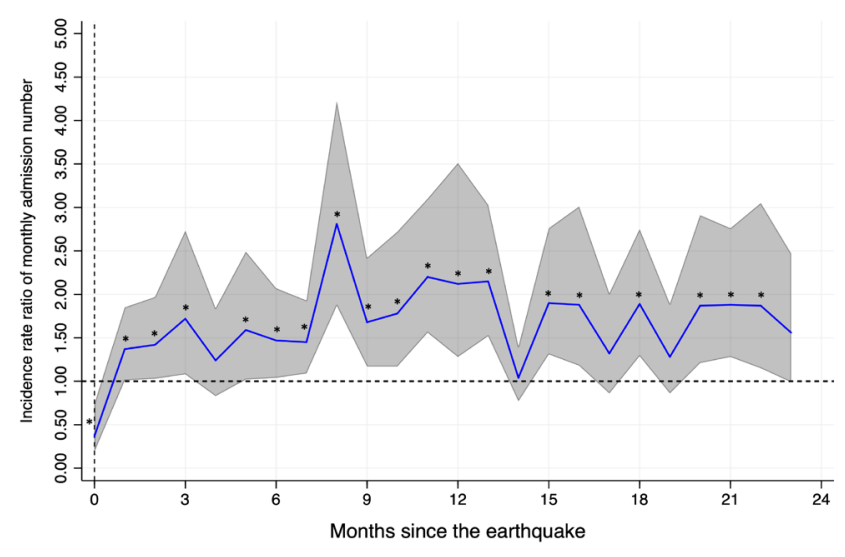

Figure 6 Time trends in the estimated incidence rate ratio for the number of monthly admissions among the patients from the less affected districts during the postdisaster period. The pre-earthquake baseline was defined as the monthly admission number from 2013 to 2015 . The incidence rate ratios were adjusted for sex and age, and the asterisk (*) indicates statistical significance at the 0.05 level.

of the districts in the LADs were more distant to TUTH compared with those in Kathmandu and the MADOKs (figure 1). Second, the destruction of basic infrastructure (eg, roads) and/or public transportation systems (eg, buses) in the MADs may have hampered visits to TUTH particularly from outside areas (figure 1). Third, the patients could have been treated at nearby hospitals instead of TUTH, though this may have been unlikely, given that only four authorised cancer hospitals (Kaski, Sunsari, Banke and Chitwan) exist in the LADs as of 2018. ${ }^{19}$ As such, some planned admissions among those from the LADs may have been cancelled or postponed at TUTH. Fourth, the patients themselves may have postponed medical consultations for symptoms related to cancer, because the urgency of such symptoms were judged to be lower than other critical problems, such as

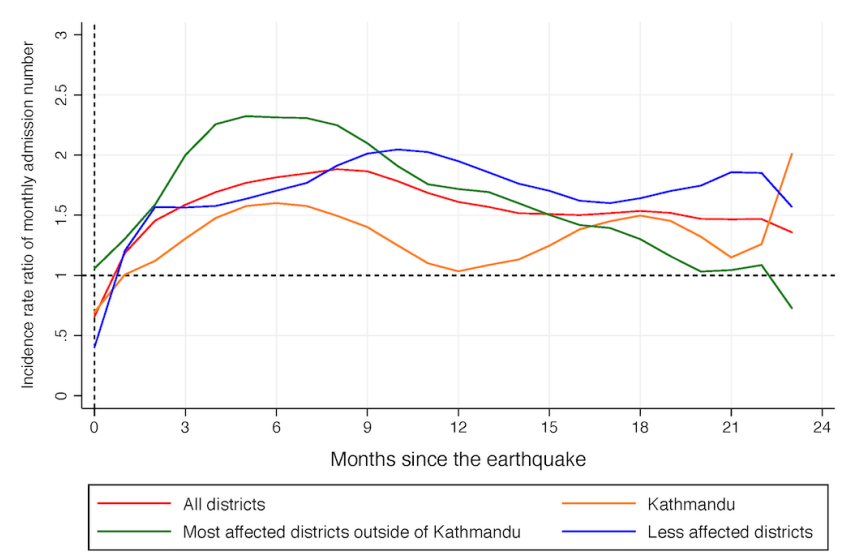

Figure 7 Time trends in the smoothed values for the incidence rate ratio for the monthly admissions during the postearthquake period. The pre-earthquake baseline was defined as the monthly admission number from 2013 to 2015. acute illnesses and material and housing issues in this disaster setting. ${ }^{28}$

Further, it is worth considering the overall situation surrounding health sectors. In the immediate aftermath of earthquakes, overall health system functioning would have been compromised via damage to physical infrastructure, medical equipment and means of communication, as well as the lack of medical and other essentials. ${ }^{29}$ Additionally, health sectors were likely overwhelmed by an increase of acute illnesses and exacerbation of non-communicable diseases. ${ }^{23}$ 25-27 Reportedly, there was limited earthquake damage to the functioning and infrastructure of TUTH. ${ }^{18}$ Yet, more than 1700 earthquake victims and 478 life-saving or limb-salvaging surgeries were undertaken in the first week at the hospital. ${ }^{18}$ Therefore, health resources specifically allocated to cancer care may have been limited in this period.

\section{Cancer care in the mid-term to long-term aftermath of the earthquake}

There was a long-term increase in admissions from the second month. Of note, there was significant variance in the extent of this increase between geographical regions: while only a slight increase in admissions was observed in patients from Kathmandu, the increase in admissions for those from LADs was more prominent and continued the longest. It is difficult to conclusively decipher the underlying mechanisms of these findings from available information. However, we speculate that the differences of restoration speed contributed to this disparity, and the chief determinants of such speed may have been the original capacity for cancer care and the amount of resources allocated to restoration work. Although six authorised cancer hospitals existed in Kathmandu, only four did in the LADs (62 districts) and their capacity for cancer care was originally restricted. ${ }^{19}$ Further, limited resources were available for restoration work, primarily due to the restricted budget of the Nepali government and economic blockade by India. ${ }^{30}$ Thus, restoration work for Kathmandu and the MADOKs, where estimated damage was more severe, may have been prioritised to that for the LADs. Resultantly, the capacity of cancer care in LADs may have remained at a low standard for a prolonged time after the earthquake, resulting in increased patients coming from LADs for treatment at TUTH.

\section{Other remarkable findings}

We also found that there was a difference in the distribution of cancer type before and after the disaster. Particularly, a postdisaster increase observed in cancer in the lymphoid, haematopoietic and related tissue was remarkable (174 postdisaster vs 11 predisaster). The most plausible explanation of this phenomenon is the postdisaster arrival of a haematology specialist at TUTH. We speculate that rather than a disaster effect, the presence of this specialist may have elevated admissions for cancer in the lymphoid, haematopoietic and related tissue. 
Possible implications for patients and global communities

Given that both delayed medical consultation and long travel distance are associated with worsened cancer outcomes, ${ }^{731}$ the earthquake may have delivered adverse health effects to patients from the LADs both in the short and long term. Those from the MADOKs may have experienced similar health effects, and significant increases in admission numbers were observed among this population during the first year. Further studies are required to comprehensively understand the implications for patients with cancer after this disaster.

This case contains several lessons on postdisaster cancer care in LMICs. Disaster recovery often happens within a context of severe restrictions in funding and resources in LMICs, and recovery speed may differ between less affected and more affected regions. The decrease in cancer patient admissions observed here in the month of the disaster (Month 0) was followed by a sharp increase from more affected regions, and a slower, yet persisting, increase from less affected regions. This may suggest that the availability of cancer care differed in less affected and more affected areas, with limited capacity for cancer care in LADs resulting in an influx of such patients coming into one of the most affected areas, where TUTH is located, in order to receive care. Access to cancer care is an important component of healthcare that should be prioritised in policies for disaster preparedness and response, and this case highlights that the geographical determinants of access to care is an important dimension to consider. There is a need to establish logistics to enable the effective distribution of material and human support for those in need of cancer care following a disaster, in both less affected and more affected areas.

\section{Limitations and future perspectives}

Two limitations should be acknowledged in this study. First and foremost, this study only included data from TUTH, and generalisability of the observed findings may be limited. Second, detailed patient information, such as clinical characteristics, process of referrals, treatment details and outcomes and experiences of the earthquakes, was not considered in this study. We also did not consider potential changes of outpatient capacity before and after the disaster. These factors are essential to assessing the clinical contexts of each admission. Thus, our findings may have been influenced by unmeasured confounding factors.

In future studies, two domains are particularly worth discussion. First, effort should be made to clarify the effect of the earthquake on cancer prognosis. In LMICs, including Nepal, less treatment modalities are available compared with HICs. ${ }^{2}$ Thus, possible delay in cancer diagnosis and treatment after a disaster experienced in LICs may deliver a more significant effect on mortality compared with that experienced in HICs; the effect of missing out on early treatment may be greater in LMICs than HICs. Second, given that there is a large disparity in the regional capacity for cancer care, we suggest that further studies are needed that involve multiple cancer hospitals in Nepal to obtain more robust findings.

\section{CONCLUSIONS}

In our study which analysed time trends in admissions among patients with cancer admitted to TUTH before and after the 2015 Nepal earthquake, the number of cancer patient admissions decreased in the first month, however was elevated beyond a predisaster level for the remainder of the 2-year study period. This trend was the most significant among the patients from the LADs, which may indicate regional differences in cancer care resources and access. Despite limited generalisability of the obtained findings, our study demonstrates important lessons regarding the cancer care in LMIC postdisaster contexts.

\section{Author affiliations}

${ }^{1}$ Department of Anesthesiology, Maharajgunj Medical Campus, Institute of Medicine, Tribhuvan University Teaching Hospital, Kathmandu, Nepal

${ }^{2}$ Research Center for Community Health, Minamisoma Municipal General Hospital, Minamisoma, Fukushima, Japan

${ }^{3}$ Department of Breast Surgery, Jyoban Hospital of Tokiwa Foundation, Iwaki,

Fukushima, Japan

${ }^{4}$ Medical Governance Research Institute, Minato-ku, Tokyo, Japan

${ }^{5}$ Department of Public Health, Fukushima Medical University School of Medicine,

Fukushima, Fukushima, Japan

${ }^{6}$ Department of Gastrointestinal and General Surgery, Maharajgunj Medical Campus, Institute of Medicine, Tribhuvan University Teaching Hospital, Kathmandu, Nepal ${ }^{7}$ Department of Surgery, Minamisoma Municipal General Hospital, Minamisoma, Fukushima, Japan

${ }^{8}$ Department of Hematology and Rheumatology, Teikyo University Chiba Medical Center, Ichihara, Chiba, Japan

${ }^{9}$ Department of Epidemiology and Biostatistics, School of Public Health, Imperial College London, London, UK

${ }^{10}$ Department of Global Health Policy, Graduate School of Medicine, University of Tokyo, Bunkyo-ku, Tokyo, Japan

${ }^{11}$ Global Public Health Unit, School of Social and Political Science, University of Edinburgh, Edinburgh, UK

${ }^{12}$ Department of Internal Medicine, Jyoban Hospital of Tokiwa Foundation, Iwaki, Fukushima, Japan

Acknowledgements We would like to thank Dr Yoshitaka Nishikawa, Dr Tsunehiko Komatsu, Dr Masahiro Kami and Mr Masatsugu Tanaki for their constructive opinions on this study.

Contributors All the authors conceived and designed the study and take responsibility for the integrity of the data and the accuracy of the data analysis. $A U, B G$, and $Y P S$ acquired the data. $A U, A O$ and $A H$ analysed and interpreted the data. AO, AH, KT and SN conducted statistical analysis. AU, AO, AH, TS, CL, MT and TT drafted the article. All the authors made critical revisions to the manuscript for important intellectual content and gave final approval of the manuscript.

Funding The authors have not declared a specific grant for this research from any funding agency in the public, commercial or not-for-profit sectors.

Map disclaimer The depiction ofboundaries on the map(s) in this article do not imply the expression of anyopinion whatsoever on the part of BMJ (or any member of its group) concerningthe legal status of any country, territory, jurisdiction or area or of itsauthorities. The map(s) are provided without any warranty of any kind, eitherexpress or implied.

Competing interests $\mathrm{AO}$ and TT report personal fees from MNES Inc., outside of the submitted work.

Patient consent for publication Not required.

Ethics approval The ethics committee of the Tribhuvan University Teaching Hospital granted approval for this study (approval number: $\left.417(6-11-\mathrm{E})^{2} / 073 / 074\right)$. 
Provenance and peer review Not commissioned; externally peer reviewed.

Data sharing statement Additional unpublished data are not publicly available.

Open access This is an open access article distributed in accordance with the Creative Commons Attribution Non Commercial (CC BY-NC 4.0) license, which permits others to distribute, remix, adapt, build upon this work non-commercially, and license their derivative works on different terms, provided the original work is properly cited, appropriate credit is given, any changes made indicated, and the use is non-commercial. See: http://creativecommons.org/licenses/by-nc/4.0/.

\section{REFERENCES}

1. Fitzmaurice C, Allen C, Barber RM, et al. Global, Regional, and National Cancer Incidence, Mortality, Years of Life Lost, Years Lived With Disability, and Disability-Adjusted Life-years for 32 Cancer Groups, 1990 to 2015: A Systematic Analysis for the Global Burden of Disease Study. JAMA Oncol 2017;3(4):524-48.

2. Jemal A, Vinela P, Bray F, et al; The Cancer Atlas. 2nd Edition. GA: American Cancer Society, 2014.

3. Macleod U, Mitchell ED, Burgess C, et al. Risk factors for delayed presentation and referral of symptomatic cancer: evidence for common cancers. Br J Cancer 2009;101(Suppl 2):S92-S101.

4. Forbes LJ, Warburton F, Richards MA, et al. Risk factors for delay in symptomatic presentation: a survey of cancer patients. $\mathrm{Br} J$ Cancer 2014;111:581-8.

5. Keeble S, Abel GA, Saunders CL, et al. Variation in promptness of presentation among 10,297 patients subsequently diagnosed with one of 18 cancers: evidence from a National Audit of Cancer Diagnosis in Primary Care. Int J Cancer 2014;135:1220-8.

6. Baldwin LM, Cai Y, Larson EH, et al. Access to cancer services for rural colorectal cancer patients. J Rural Health 2008;24:390-9.

7. Murphy CT, Galloway TJ, Handorf EA, et al. Survival Impact of Increasing Time to Treatment Initiation for Patients With Head and Neck Cancer in the United States. J Clin Oncol 2016;34:169-78.

8. Eckstein D, Künzel V, Schuäfer L. GLOBAL CLIMATE RISK INDEX 2018: Who Suffers Most From Extreme Weather Events? Weatherrelated Loss Events in 2016 and 1997 to 2017;2016 https:// germanwatch.org/en/download/20432.pdf.

9. Forzieri G, Cescatti A, E Silva FB, et al. Increasing risk over time of weather-related hazards to the European population: a data-driven prognostic study. Lancet Planet Health 2017;1:e200-e208.

10. David-West G, Musa F, Frey MK, et al. Cross-Sectional Study of the Impact of a Natural Disaster on the Delivery of Gynecologic Oncology Care. Disaster Med Public Health Prep 2015;9:605-8.

11. Morita T, Nomura S, Tsubokura M, et al. Excess mortality due to indirect health effects of the 2011 triple disaster in Fukushima, Japan: a retrospective observational study. J Epidemiol Community Health 2017;71:974-80.

12. Ozaki A, Tsubokura M. Radiation Oncology and Related Oncology Fields in the Face of the 2011 "Triple Disaster" in Fukushima, Japan. Int J Radiat Oncol Biol Phys 2018;100:845-8.

13. Ozaki A, Nomura S, Leppold C, et al. Breast cancer patient delay in Fukushima, Japan following the 2011 triple disaster: a long-term retrospective study. BMC Cancer 2017;17:423.

14. Mishra SR, Khanal V, Kallestrup P. Cancer in the aftermath of Nepal's earthquakes. Lancet Oncol 2016;17:705-6.
15. The World Bank. GNI per capita, Atlas method 2016 https://data. worldbank.org/indicator/NY.GNP.PCAP.CD?order=wbapi_data value_2014+wbapi_data_value+wbapi_data_value-last\&sort=-desc (accessed 24 March 2018).

16. Poudel KK, Huang Z, Neupane PR, et al. Changes in the Distribution of Cancer Incidence in Nepal from 2003 to 2013. Asian Pac J Cancer Prev 2016;17:4775-82.

17. Adhikari B, Mishra SR, Raut S. Rebuilding Earthquake Struck Nepal through Community Engagement. Front Public Health 2016;4:121.

18. Aryal D, Acharya SP, Shrestha GS, et al. Nepal after the disaster. Insider points of view for the future of critical care medicine. Am J Respir Crit Care Med 2015;192:781-4.

19. Poudel KK, Huang Z, Neupane PR, et al. Hospital-Based Cancer Incidence in Nepal from 2010 to 2013. Nepal J Epidemiol 2017;7:659-65.

20. World Health Organization. Emergency preparedness pays off as Kathmandu hospitals respond to earthquakes. $2015 \mathrm{http}: / / w w w$. who.int/mediacentre/news/releases/2015/nepal-second-quake/en/ (accessed 24 March 2018).

21. On-Site Operations Coordination Centre, United Nations Office for the Coordination of Humanitarian Affairs. Situation Analysis Nepal Earthquake. 2015 https://reliefweb.int/sites/reliefweb.int/files/ resources/150515_nepal_situation_analysis_osocc_assessmente_ cell___final_final.pdf (accessed 24 March 2018).

22. The Government of Nepal. Nepal Earthquake Housing Reconstruction Multi-donor Trust Fund https://www.nepalhousingreconstruction.org/ (accessed 24 March 2018).

23. Aoki T, Fukumoto Y, Yasuda S, et al. The Great East Japan Earthquake Disaster and cardiovascular diseases. Eur Heart J 2012;33:2796-803.

24. Weaver CG, Ravani P, Oliver MJ, et al. Analyzing hospitalization data: potential limitations of Poisson regression. Nephrol Dial Transplant 2015;30:1244-9

25. Yamanda S, Hanagama M, Kobayashi S, et al. The impact of the 2011 Great East Japan Earthquake on hospitalisation for respiratory disease in a rapidly aging society: a retrospective descriptive and cross-sectional study at the disaster base hospital in Ishinomaki. BMJ Open 2013;3(1):e000865.

26. Aoki T, Takahashi J, Fukumoto Y, et al. Effect of the Great East Japan Earthquake on cardiovascular diseases--report from the 10 hospitals in the disaster area. Circ J 2013;77:490-3.

27. Kanno T, lijima K, Abe Y, et al. Peptic ulcers after the Great East Japan earthquake and tsunami: possible existence of psychosocial stress ulcers in humans. J Gastroenterol 2013;48:483-90.

28. Gorji HA, Jafari H, Heidari M, et al. Cancer Patients During and after Natural and Man-Made Disasters: A Systematic Review. Asian Pac J Cancer Prev 2018;19:2695-700.

29. Kodama Y, Oikawa T, Hayashi K, et al. Impact of natural disaster combined with nuclear power plant accidents on local medical services: a case study of Minamisoma Municipal General Hospital after the Great East Japan Earthquake. Disaster Med Public Health Prep 2014;8:471-6.

30. Lamichhane J. Health consequences of the blockade in Nepal. Lancet 2015;386:2251.

31. Massarweh NN, Chiang YJ, Xing Y, et al. Association between travel distance and metastatic disease at diagnosis among patients with colon cancer. J Clin Oncol 2014;32:942-8. 